\title{
Predictors for Visual Outcomes in Eye Injuries with Intraocular Foreign Body
}

This article was published in the following Dove Press journal: Clinical Ophthalmology

\author{
Tanapat Ratanapakorn' \\ Parichat Kongmalai ${ }^{2}$ \\ Suthasinee Sinawat ${ }^{\prime}$ \\ Thuss Sanguansak (D) \\ Chavakij Bhoomibunchoo' \\ Wipada Laovirojjanakul $\mathbb{D}^{\prime}$ \\ Yosanan Yospaiboon (1D) \\ 'KKU Eye Center, Department of \\ Ophthalmology, Faculty of Medicine, \\ Khon Kaen University, Khon Kaen, \\ Thailand; ${ }^{2}$ Chaophrayayommarat \\ Hospital, Suphanburi, Thailand
}

\begin{abstract}
Objective: To study the visual outcomes and identify the predictive factors for visual outcomes in patients with eye injuries and retained intraocular foreign bodies (IOFBs).

Patients and Methods: The medical records of 359 consecutive patients with eye injuries and retained IOFBs were retrospectively reviewed during 2009-2018. Demographic data, clinical findings, treatment and visual outcomes were studied. Univariate and multivariate analyses were used to identify the predictive factors.

Results: Most of the patients were male and the average age was 36.4 years old. The three most common causes of eye injuries were grass trimming $(25.07 \%)$, chiseling $(23.12 \%)$ and hammering (13.93\%). Most of the patients $(79.39 \%)$ presented with poor initial bestcorrected visual acuity (BCVA) $(<3 / 60)$. Pars plana vitrectomy with IOFB removal was done in 273 eyes $(76.04 \%)$. After treatment, eyes with poor BCVA $(<3 / 60)$ decreased from $79.39 \%$ to $62.95 \%$ and eyes with good BCVA ( $\geq 3 / 60$ ) increased from $20.61 \%$ to $37.05 \%$. Poor initial best-corrected visual acuity (odds ratio 23.39, $\mathrm{P}<0.001$ ), rhegmatogenous retinal detachment (odds ratio 9.91, $\mathrm{P}<0.001$ ) and the presence of infectious endophthalmitis (odds ratio $2.06, \mathrm{P}=0.02$ ) were statistically significant predictive factors for poor visual outcome. Conclusion: Most patients with eye injuries and IOFBs usually have poor final BCVA. Poor presenting BCVA, retinal detachment and endophthalmitis are significant predictive factors for poor visual outcomes. These factors can be used to inform the visual prognosis and plan prompt surgical intervention for the patients. Causes of IOFBs were mostly work-related and could be preventable. Education and activation of using appropriate protective safety glasses during work are necessary to avoid serious eye injuries and blindness.
\end{abstract}

Keywords: intraocular foreign body, eye injury, predictive factors, visual outcome

\section{Introduction}

Intraocular foreign bodies (IOFBs) have been reported in $17-41 \%$ of penetrating ocular injuries and frequently cause severe visual loss in the patients with ocular trauma. ${ }^{1}$ Previous studies have reported that the majority of IOFBs are workrelated, ${ }^{2,3}$ and the most common cause is hammering. ${ }^{3,4}$ Ocular damage may be caused by initial direct impact of the injuries and IOFBs such as wound laceration and intraocular hemorrhages, and consequences such as retinal detachment and endophthalmitis. Various factors have been shown to be associated with a final visual outcome following management of ocular injuries with IOFBs. These factors included presenting visual acuity, ${ }^{5-12}$ size and location of IOFB, ${ }^{7,10-15}$ intraocular hemorrhage, ${ }^{1,6,11,16}$ retinal detachment ${ }^{1,8,10,11,15-17}$ and endophthalmitis. ${ }^{9,11,12}$ Some studies revealed that size and location of wound entry affected a final visual acuity, ${ }^{3,5,10-13,17}$ whereas other studies showed that presence of relative afferent
Correspondence: Yosanan Yospaiboon KKU Eye Center, Department of Ophthalmology, Faculty of Medicine, Khon Kaen University, 123 Mitraparb Highway, Khon Kaen 40002, Thailand Tel +6643348383

Email yyosanan@gmail.com 
pupillary defect (RAPD) was related to the final visual outcome. ${ }^{3,6,16}$ However, there was no consensus on these predictive factors in patients with IOFBs and most studies had a too limited sample size to draw a definite conclusion. Therefore, this study was intended to determine predictive factors for final visual outcomes in a larger series of patients with eye injuries and retained IOFBs.

\section{Patients and Methods}

This study follows the tenets of the Declaration of Helsinki, the ICH Good Clinical Practice Guidelines and was approved by the Khon Kaen University Ethics Committee for Human Research (HE591020). The medical records of consecutive patients with ocular injuries and IOFBs at KKU Eye Center during 10 years (2009-2018) were retrospectively reviewed. Although patient consent to review their medical records was not required by the ethics committee, the data in case report forms nevertheless had no linkage to the patient identities and the patient data confidentiality was protected. Data on demographic characteristics, clinical findings and the treatment outcomes were collected. The demographic data included patient's age, gender, mechanism of injury and whether the patient was wearing an eye protective device at the time of injury. The clinical findings consisted of initial examination, site of eye injury, initial best-corrected visual acuity (BCVA), the time from injury to IOFB removal, location of the wound entrance, types of IOFB (metallic or non-metallic), relative afferent pupillary defect (RAPD) and other complications of ocular injuries. The treatment outcome data included final BCVA at a follow-up period of 6 months, and whether the patient had evisceration or enucleation or not. Patients who had a follow-up period of less than 6 months were excluded from the study. These data were collected and a crosscheck for errors was conducted by double data entry. If a variable could not be identified or was missing in the record, the data were also excluded from this study.

\section{Statistical Analyses}

All input data were analyzed using SPSS software version 17.0 (SPSS, Inc, Chicago, Illinois, USA). Categorical variables were analyzed using the chi-square test. Continuous variables were evaluated for normality, and means were compared using $t$-test. Univariate and multivariate analyses were conducted by logistic regression to evaluate the predictive factors. A $\mathrm{P}$ value of less than 0.05 was considered statistically significant for all tests.

\section{Results}

Of the 359 patients recruited in this study, 335 were male $(93.31 \%)$ and 24 were female $(6.69 \%)$. The age ranged from 3 to 83 years with a mean of $36.4 \pm 15.9$ years. There were 173 right eyes (48.19\%) and 186 left eyes (51.81\%). Almost all of them $(349 ; 97.21 \%)$ did not wear eye protective devices. The hospital stay ranged from 1-26 days with a mean of $5.8 \pm 3.8$ days. The three most common causes of eye injuries were grass trimming using a handheld powered tool, which accounted for $25.07 \%$, followed by chiseling (23.12\%) and hammering (13.93\%). Firecracker explosion was commonly noted in children. Seventy-five bystanders $(20.89 \%)$ who were present at the incident had eye injuries though they did not take part. Other demographic data of patients in the study are shown in Table 1.

The wound entry sites for IOFBs were divided into three zones, among which zone 1 was cornea, zone 2 was the area surrounding the cornea extending from corneoscleral line to $5 \mathrm{~mm}$ from the limbus and zone 3 represented scleral wound beyond $5 \mathrm{~mm}$ from the limbus. Corneal wound (zone 1) was the most common site of entry for IOFB (276 eyes; 76.88\%). Scleral site of entry for IOFB (zones 2 and 3) was observed in 83 eyes $(23.12 \%)$. Most IOFBs $(82.45 \%)$ were located in the posterior segment (behind the lens equator). The three most common sites of injuries were corneal injury (295 eyes; $82.17 \%$ ), lens injury (252 eyes; $70.19 \%$ ) and iris injury

Table I Demographic Data of Patients in the Study

\begin{tabular}{|l|l|l|}
\hline & Number & Percent \\
\hline Gender: Male & 335 & 93.31 \\
Affected eye: Left & 186 & 51.81 \\
Eye protection: No & 349 & 97.21 \\
\hline Occupation & & \\
Agriculturist & 134 & 37.33 \\
Mechanic & 101 & 28.13 \\
Laborer & 55 & 15.32 \\
Student & 43 & 11.98 \\
Office worker & 20 & 5.57 \\
Carpenter & 4 & 1.11 \\
Housewife & 2 & 0.56 \\
\hline Causes of injury & & \\
Grass trimming & 90 & 25.07 \\
Chiseling & 83 & 23.12 \\
Hammering & 50 & 13.93 \\
Firecracker explosion & 43 & 11.98 \\
Others & 18 & 5.01 \\
Bystanders & 75 & 20.89 \\
\hline
\end{tabular}


(226 eyes; 62.95\%). Retinal injuries included retinal break without detachment (162 eyes; 45.13\%), rhegmatogenous retinal detachment without macular involvement (88 eyes; $24.51 \%$ ) and those with macular involvement (18 eyes; $5.01 \%)$. Endophthalmitis was noted in 135 eyes $(37.60 \%)$. Relative afferent pupillary defect was present in 170 eyes $(47.35 \%)$. Other clinical findings and complications are shown in Table 2.

Of 359 patients, 4 patients refused to have surgical interventions. Two patients had double perforation and foreign bodies in the orbit. Therefore, only 353 patients were planned for IOFB removal. IOFBs were not removed in 6 eyes due to thick encapsulated fibrous tissue (3 eyes) and unidentified IOFBs during surgery ( 3 eyes). Only 38 eyes $(10.76 \%)$ were operated on within 24 hours after the injury, whereas delayed surgery after 24 hours was noted in 315 eyes (89.24\%). Of 347 IOFBs removed, metallic IOFBs were noted in 259 (74.64\%) eyes, whereas non-metallic IOFBs including glass or vegetative matters or firecracker explosive chemicals were observed in $88(25.36 \%)$ eyes. IOFBs were located in the anterior segment (63 eyes) and posterior segment (296 eyes). IOFBs were removed during primary repair in $80(22.28 \%)$ eyes. Pars plana vitrectomy

Table 2 Clinical Findings of Patients in the Study

\begin{tabular}{|l|l|l|}
\hline & Number & Per Cent \\
\hline Wound entry sites & & \\
Zone I & 276 & 76.88 \\
Zone 2 & 61 & 16.99 \\
Zone 3 & 22 & 6.13 \\
\hline Sites of injury & & \\
Corneal injury & 295 & 82.17 \\
Lens injury & 252 & 70.19 \\
Iris injury & 226 & 62.95 \\
Retinal break & 162 & 45.13 \\
Endophthalmitis & 135 & 37.60 \\
Vitreous hemorrhage & 133 & 37.05 \\
Retinal detachment & 106 & 29.53 \\
Scleral injury & 88 & 24.51 \\
Hyphema & 81 & 22.56 \\
Hypopyon & 47 & 13.09 \\
Eyelid injury & 27 & 7.52 \\
Choroidal detachment & 15 & 4.18 \\
Canalicular injury & 2 & 0.56 \\
\hline Complications & & \\
Secondary glaucoma & 38 & 10.58 \\
Atrophic/phthisis bulbi & 28 & 7.80 \\
Siderosis bulbi & 22 & 6.13 \\
Sympathetic ophthalmia & 2 & 0.56 \\
\hline
\end{tabular}

Table 3 Initial and Final BCVA of Patients in the Study

\begin{tabular}{|l|l|l|l|l|}
\hline \multirow{2}{*}{ Snellen Visual Acuity } & \multicolumn{2}{|l|}{ Initial BCVA } & \multicolumn{2}{l|}{ Final BCVA } \\
\cline { 2 - 5 } & No. & Percent & No. & Percent \\
\hline$\geq 6 / 18$ & 34 & 9.47 & 75 & 20.89 \\
\hline$<6 / 18-6 / 60$ & 33 & 9.19 & 55 & 15.32 \\
\hline$<6 / 60-3 / 60$ & 7 & 1.95 & 3 & 0.84 \\
\hline$<3 / 60-C F$ & 46 & 12.81 & 39 & 10.86 \\
\hline CF-LP & 191 & 53.21 & 81 & 22.56 \\
\hline NLP & 48 & 13.37 & 106 & 29.53 \\
\hline
\end{tabular}

was performed in 273 (76.04\%) eyes, with vitrectomy combined with expansile gas tamponade in 48 eyes and combined with silicone oil tamponade in 82 eyes. Retinal breaks at the site of IOFBs were treated with endolaser photocoagulation in 140 eyes, cryoretinopexy in 5 eyes and combined treatment in 17 eyes. Lens removal was performed at the time of vitrectomy in 209 eyes, of which 92 eyes had primary intraocular lens implantation. For eyes complicated by endophthalmitis, all 135 eyes $(37.60 \%)$ were surgically treated by vitrectomy and received intravitreal injection of vancomycin and ceftazidime. Intracameral and subconjunctival antibiotics were also administered. Seventy-seven eyes (21.45\%) were eviscerated. Of these 77 eyes, 17 eyes had primary evisceration due to uncontrolled severe infection and no light perception, whereas 60 eyes were eviscerated as a second operation.

Initial and final BCVA of patients in the study are shown in Table 3 and Figure 1. Two hundred and eighty-five eyes $(79.39 \%)$ presented with poor initial BCVA $(<3 / 60)$. The

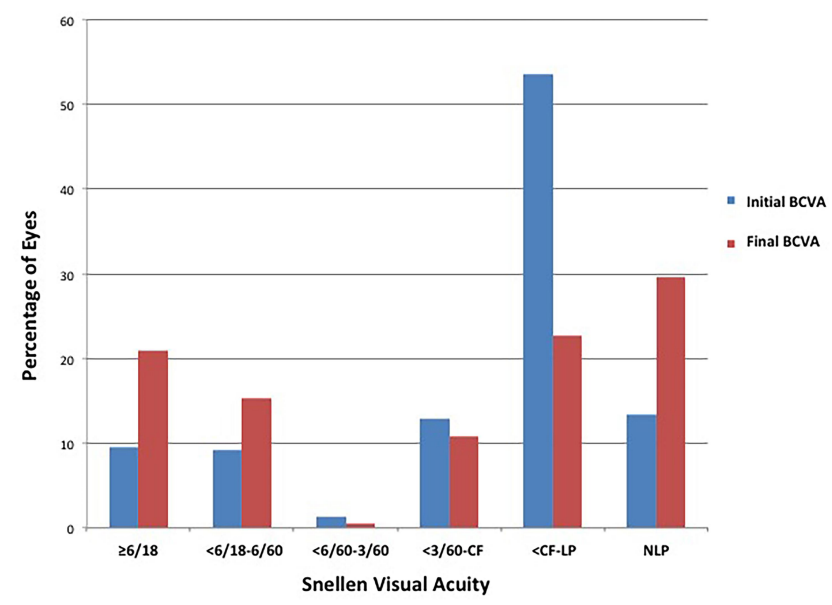

Figure I Initial and final best-corrected visual acuity (BCVA) of patients in the study. 
most common initial BCVA was counting fingers to light perception (CF-LP) (191 eyes; 53.21\%), followed by no light perception (NLP) (48 eyes; $13.37 \%$ ) and $<3 / 60$ to counting fingers (CF) (46 eyes; 12.81\%). After treatment, poor BCVA $(<3 / 60)$ decreased from 285 eyes $(79.39 \%)$ to 226 eyes (62.95\%). After treatment, all 48 eyes with no light perception and 58 eyes with light perception ended up with no light perception (106 eyes; $29.53 \%$ ). The number of eyes with BCVA of $\geq 6 / 18$ increased from 34 eyes $(9.47 \%)$ to 75 eyes $(20.89 \%)$ whereas eyes with BCVA from $<6 / 18$ to $6 / 60$ increased from 33 eyes $(9.19 \%)$ to 55 eyes $(15.32 \%)$ (Table 3, Figure 1).

Using univariate regression analysis, the factors that were significantly associated with poor visual outcome $(\mathrm{VA}<3 / 60)$ included poor initial BCVA $(\mathrm{P}<0.001)$, scleral injury $(\mathrm{P}=0.008)$, hyphema $(\mathrm{P}<0.001)$, presence of relative afferent pupillary defect $(\mathrm{RAPD})(\mathrm{P}<0.001)$, rhegmatogenous retinal detachment (RRD) without macular involvement $(\mathrm{P}<0.001)$, RRD with macular involvement $(\mathrm{P}=0.028)$ and endophthalmitis $(\mathrm{P}=0.005)$ (Table 4$)$. After adjusting with multivariate analysis, poor initial BCVA, RRD and endophthalmitis were found to be statistically significant predictors for poor visual outcome after treatment (Table 5).

\section{Discussion}

In this study, we reviewed the demographic data and clinical findings, final visual outcome and predictive factors for visual outcomes in patients with ocular injuries and retained IOFBs. The results demonstrated that eye injuries with IOFBs commonly occurred in agriculturists, mechanics and laborers in the order of descending frequency. The three most common causes of the injuries were grass trimming, chiseling and hammering. These findings were different from previous studies that revealed mechanic as the most common occupation and hammering as the most common cause of injuries. ${ }^{2-4}$ Thailand is an agricultural country and the majority of the population are agriculturists. After the harvest, many of them are employed for a part-time job, commonly grass cutting. A hand-held trimmer is commonly used for cutting grass because it is more economical than a lawn mower. It is a garden tool using a flexible monofilament line, a plastic blade or a metal blade. It consists of a rotating spindle at the end of a long shaft with a handle. The principle of centrifugal force makes it spin fast enough to cut grass. However, it can send debris or foreign bodies on the ground flying at high velocity, and in random directions. It is therefore recommended to wear safety glasses for
Table 4 Univariate Analysis of Predictors for Final Visual Outcome

\begin{tabular}{|c|c|c|c|}
\hline \multirow{2}{*}{$\begin{array}{l}\text { Predictors for Visual } \\
\text { Outcome }\end{array}$} & \multicolumn{2}{|c|}{ Final BCVA } & \multirow[t]{2}{*}{ P-value } \\
\hline & $\begin{array}{l}>3 / 60 \\
\text { No. (\%) }\end{array}$ & $\begin{array}{l}\leq 3 / 60 \\
\text { No. (\%) }\end{array}$ & \\
\hline \multicolumn{4}{|l|}{ Initial VA $(n=359)$} \\
\hline Poor $(\leq 3 / 60)$ & 71 (53.38) & $214(94.69)$ & $<0.001$ \\
\hline Good $(>3 / 60)$ & $62(46.62)$ & $12(5.3 \mathrm{I})$ & \\
\hline \multicolumn{4}{|l|}{ Sites of wound entry $(n=359)$} \\
\hline Zone I & $103(79.03)$ & $173(76.21)$ & 0.749 \\
\hline Zones 2, 3 & $29(21.97)$ & $54(23.79)$ & \\
\hline \multicolumn{4}{|l|}{ Location of IOFB $(n=359)$} \\
\hline Anterior & $29(21.97)$ & $34(14.98)$ & 0.097 \\
\hline Posterior & $103(78.03)$ & $193(85.02)$ & \\
\hline \multicolumn{4}{|l|}{ Type of IOFB $(n=347)$} \\
\hline Metallic & $102(78.46)$ & $157(72.35)$ & 0.111 \\
\hline Non-metallic & $28(21.54)$ & $60(27.65)$ & \\
\hline \multicolumn{4}{|l|}{ Time to IOFB removal $(n=353)$} \\
\hline$\leq 24 \mathrm{hr}$ & $13(10.0)$ & $25(11.21)$ & 0.157 \\
\hline$>24 \mathrm{hr}$ & $117(90.0)$ & 198 (88.79) & \\
\hline \multicolumn{4}{|l|}{ Scleral injury $(n=359)$} \\
\hline Yes & $22(16.54)$ & $66(29.20)$ & 0.008 \\
\hline No & III (83.46) & $160(70.80)$ & \\
\hline \multicolumn{4}{|l|}{ Hyphema $(n=359)$} \\
\hline Yes & II (8.27) & $70(30.97)$ & $<0.001$ \\
\hline No & $122(91.73)$ & $156(69.03)$ & \\
\hline \multicolumn{4}{|l|}{ Hypopyon $(n=359)$} \\
\hline Yes & $14(10.53)$ & $33(14.60)$ & 0.280 \\
\hline No & $119(89.47)$ & $193(85.40)$ & \\
\hline \multicolumn{4}{|l|}{$\begin{array}{l}\text { Relative afferent pupillary defect } \\
(n=359)\end{array}$} \\
\hline Positive & $25(20.66)$ & $145(60.92)$ & $<0.001$ \\
\hline Negative & $96(79.34)$ & $93(39.08)$ & \\
\hline \multicolumn{4}{|l|}{ Retinal detachment $(n=359)$} \\
\hline Yes & $16(12.12)$ & $90(39.65)$ & $<0.001$ \\
\hline No & II 6 (87.88) & $137(60.35)$ & \\
\hline \multicolumn{4}{|l|}{ Vitreous hemorrhage $(n=359)$} \\
\hline Yes & $45(33.83)$ & $88(38.94)$ & 0.36 \\
\hline No & $88(66.17)$ & $138(61.06)$ & \\
\hline \multicolumn{4}{|l|}{ Endophthalmitis ( $n=359)$} \\
\hline Yes & $37(28.03)$ & $98(43.17)$ & 0.005 \\
\hline No & 95 (7I.97) & $129(56.83)$ & \\
\hline \multicolumn{4}{|l|}{ Siderosis bulbi $(n=359)$} \\
\hline Yes & $8(6.06)$ & $14(6.17)$ & 0.959 \\
\hline No & $124(93.94)$ & $213(93.83)$ & \\
\hline
\end{tabular}

protection. Nevertheless, passers-by can have accidental eye injuries with IOFBs. Our study showed that 75 patients $(20.89 \%)$ who were just innocent bystanders or 
Table 5 Multivariate Analysis of Predictors for Final Visual Outcome

\begin{tabular}{|c|c|c|c|c|c|}
\hline \multirow[t]{2}{*}{ Predictors for Visual Outcome } & \multicolumn{2}{|l|}{ Final BCVA } & \multirow[t]{2}{*}{ Odds Ratio } & \multirow[t]{2}{*}{$95 \% \mathrm{Cl}$} & \multirow[t]{2}{*}{ P-value } \\
\hline & $>3 / 60$ No. (\%) & $\leq 3 / 60$ No. (\%) & & & \\
\hline \multicolumn{6}{|l|}{ Initial VA } \\
\hline Poor $(\leq 3 / 60)$ & 71 (53.38) & $214(94.69)$ & 23.39 & $9.52-57.46$ & $<0.001$ \\
\hline Good $(>3 / 60)$ & $62(46.62)$ & $12(5.31)$ & & & \\
\hline \multicolumn{6}{|l|}{ Retinal detachment } \\
\hline Yes & $16(12.12)$ & $90(39.65)$ & 9.91 & $3.93-24.97$ & $<0.001$ \\
\hline No & II $6(87.88)$ & $137(60.35)$ & & & \\
\hline \multicolumn{6}{|l|}{ Endophthalmitis } \\
\hline Yes & $37(28.03)$ & $98(43.17)$ & 2.06 & I. I2-3.77 & 0.02 \\
\hline No & 95 (7I.97) & $129(56.83)$ & & & \\
\hline
\end{tabular}

passers-by in the nearby area had eye injuries with IOFBs. Moreover, the study also revealed that 349 patients $(97.21 \%)$ did not wear eye protective devices. This problem was similar to some previous studies. ${ }^{3,14}$ These trimmer-induced eye injuries are therefore a significant cause of eye injuries with IOFBs and result in serious visual impairment. However, these eye injuries are preventable with proper eye protection and education.

Ocular trauma with retained IOFBs was significantly associated with poor visual outcomes. ${ }^{3-6}$ Previous studies demonstrated a variety of prognostic factors to be associated with final visual outcomes following management of ocular injuries with IOFBs. ${ }^{1,3,5-17}$ However, there was no consensus on these predictive factors and most studies had sample sizes that were too limited to draw definite conclusions. There was only one study which evaluated prognostic factors in a large number of patients with ocular injuries and retained IOFBs in China. ${ }^{12}$

Presenting visual acuity was one of the common prognostic factors that related to the final visual outcomes in some previous studies. ${ }^{5-12}$ Our study also demonstrated that initial visual acuity was associated with the final visual outcomes. Most patients (95.11\%) with poor visual outcome after treatment had poor initial BCVA $(\mathrm{P}<0.001)$. This result was in accordance with previous studies. ${ }^{5-12}$ Although the majority of our patients had poorer initial visual acuities than those reported in other previous studies, ranging from counting fingers to no light perception, the number of eyes with poor BCVA $(\leq 3 / 60)$ decreased whereas those with good BCVA $(>3 / 60)$ increased after treatment.

Some studies revealed that wound entry sites affected final visual acuity. ${ }^{3,5,10-13,17}$ In our study, although 64 patients with scleral wound entry (zones 2 and 3) had poor visual outcomes $(\leq 3 / 60)$, and 29 patients ended with good vision $(>3 / 60)$ after treatment, this difference, showed no statistical significance. On the contrary, 66 eyes with scleral injury had poor vision $(\leq 3 / 60)$ whereas 22 eyes resulted in good vision $(>3 / 60)$ after treatment. This finding showed that scleral injury was related to poor final visual outcome with statistical significance $(\mathrm{P}=0.008)$. However, it demonstrated no statistically significant association after adjusting with multivariate analysis.

Jonas et al. reported that type of IOFB was one of the prognostic factors for final visual outcome. ${ }^{7}$ Our study, however, demonstrated no statistically significant association with visual outcome. Some previous studies revealed that posterior segment location of IOFB was related to the final visual outcome in patients with eye injuries and retained IOFB; ${ }^{10,12}$ our study, however, did not show any statistically significant association.

Relative afferent pupillary defect and intraocular hemorrhage were reported to be prognostic factors by some previous studies. $1,3,6,11,16$ Wickham et al. revealed that hyphema and vitreous hemorrhage were prognostic factors associated with final visual outcomes after treatment, ${ }^{16}$ whereas Greven et al. and Thoongsuwan et al. showed that vitreous hemorrhage was one of the prognostic factors in their studies. ${ }^{6,11}$ Our study, however, demonstrated that hyphema was associated with final visual outcomes in univariate analysis, but had no statistically significant association after adjusting with multivariate analysis. For RAPD, our study also demonstrated a significant association with final visual outcomes in univariate analysis. However, after multivariate analysis, it had no statistically significant association with final visual outcomes. 
Retinal detachment was also one of the prognostic factors in many previous studies. ${ }^{1,8,10,11,15-17}$ Ninety patients with RRD in our study ended treatment with poor visual acuity $(\leq 3 / 60)$, whereas 16 patients resulted in good visual outcome $(>3 / 60)$. The larger series of patients in our study confirmed this prognostic factor in both univariate and multivariate regression analyses.

Endophthalmitis was also reported to be a significant prognostic factor by some previous studies. ${ }^{9,11,12}$ Our study also confirmed this prognostic factor in both univariate and multivariate regression analyses. Interestingly, the rate of endophthalmitis $(37.60 \%)$ in our study was much higher than those reported in previous studies, which revealed incidence rates from $6.3 \%$ to $16.3 \%$ in patients with eye injuries and retained IOFBs. ${ }^{3,9,12,18-20}$ This may reflect the severity of eye injuries with posterior segment involvement in our study. Another explanation was that our eye center is a tertiary center, to which surrounding hospitals have to refer their complicated cases. This results in a delay before the patients arrive at our center and delayed time for the removal of IOFBs. The results also indicated that most patients in our study had delayed surgical intervention of more than 24 hours. Moreover, there was a tendency of increased risk of endophthalmitis when treatment was delayed for more than 24 hours after injury. ${ }^{13,21}$

The strength of our study is that the number of patients for analysis is larger than those in the previous reports. This allows more accuracy in the regression analysis of the predictive factors. The limitation is the retrospective design, in that there may be some missing data, especially the size of IOFBs, culture of vitreous specimens in endophthalmitis and proliferative vitreoretinopathy (PVR). There were incomplete records on measurement of size of IOFBs and PVR in our study. The positive yield of vitreous culture was also limited. In addition, most patients were referred from other remote hospitals after failure of treatment. This might be a selection bias to have more severe cases in our study. A further prospective clinical study in a large series of patients and a longer period of follow-up is therefore warranted.

In conclusion, most eye injuries with IOFBs are workrelated. The three most common causes of eye injuries were grass trimming, chiseling and hammering. Poor presenting BCVA, retinal detachment and presence of infectious endophthalmitis were important predictive factors for poor visual outcomes. These factors can be used to inform the visual prognosis to the patients and relatives. They also help with diagnostic decision-making and planning for prompt intervention strategies to improve the final anatomical and functional outcomes. Moreover, the distribution of retinal specialists to remote hospitals would shorten the time of referral and prompt surgical treatment could be performed. Education and activation of using appropriate protective safety glasses during work are necessary to avoid serious eye injuries and blindness. It is expected that the incidence of eye injuries with IOFBs, the rate of endophthalmitis and other serious complications would certainly be reduced following protective measures. An improvement in final visual outcomes after treatment is also anticipated.

\section{Acknowledgments}

The authors thank Dr. Kaewjai Thepsuthammarat, Clinical Epidemiology Unit, Faculty of Medicine, Khon Kaen University for statistical analysis. This study was supported by invitation research grant from the Faculty of Medicine, Khon Kaen University.

\section{Disclosure}

The authors report no conflicts of interest in this work.

\section{References}

1. Erakgun T, Egrilmez S. Prognostic factors in vitrectomy for posterior segment intraocular foreign bodies. $J$ Trauma. 2008;64 (4):1034-1037. doi:10.1097/TA.0b013e318047dff4

2. Kanoff J, Turalba A, Andreoli M, Andreoli C. Characteristics and outcomes of work-related open globe injuries. Am J Ophthalmol. 2010;150(2):265-269. doi:10.1016/j.ajo.2010.02.015

3. Choovuthayakorn J, Hansapinyo L, Ittipunkul N, Patikulsila D, Kunavisarut P. Predictive factors and outcomes of posterior segment intraocular foreign bodies. Eye. 2011;25(12):1622-1626. doi:10. 1038/eye.2011.229

4. Ehlers J, Kunimoto D, Ittoop S, Maguire J, Ho A, Regillo C. Metallic intraocular foreign bodies: characteristics, interventions, and prognostic factors for visual outcome and globe survival. $\mathrm{Am}$ J Ophthalmol. 2008;146(3):427-433. doi:10.1016/j.ajo.2008.05.021

5. Punnonen E, Laatikainen L. Prognosis of perforating eye injuries with intraocular foreign bodies. Acta Ophthalmol Scand. 1989;67 (5):483-491. doi:10.1111/j.1755-3768.1989.tb04097.x

6. Greven CM, Engelbert NE, Slusher SS, Nagy SS. Intraocular foreign bodies. Management, prognostic factors and visual outcomes. Ophthalmology. 2000;107(3):608-612. doi:10.1016/S0161-6420(99) 00134-7

7. Jonas J, Knorr H, Budde W. Prognostic factors in ocular injuries caused by intraocular or retrobulbar foreign bodies. Ophthalmology. 2000;107(5):823-828. doi:10.1016/S0161-6420(00)00079-8

8. Wani V, Al-Ajmi M, Thalib L, et al. Vitrectomy for posterior segment intraocular foreign bodies: visual results and prognostic factors. Retina. 2003;23(5):654-660. doi:10.1097/00006982-200310000-00008

9. Szijártó Z, Gaál V, Kovács B, Kuhn F. Prognosis of penetrating eye injuries with posterior segment intraocular foreign body. Graefes Arch Clin Exp Ophthalmol. 2007;246(1):161-165. doi:10.1007/ s00417-007-0650-1

10. Bai HQ, Yao L, Meng XX, Wang YX, Wang DB. Visual outcome following intraocular foreign bodies: a retrospective review of 5-year clinical experience. Eur $J$ Ophthalmol. 2011;21(1):98-103. doi:10.5301/EJO.2010.2210 
11. Thoongsuwan S, Rodanant N, Namatra C, et al. Visual outcome and prognostic factors in posterior segment intraocular foreign bodies. J Med Assoc Thai. 2012;95(4):82-86.

12. Zhang Y, Zhang M, Jiang C, Qiu HY. Intraocular foreign bodies in China: clinical characteristics, prognostic factors, and visual outcomes in 1421 eyes. Am $J$ Ophthalmol. 2011;152(1):66-73. doi:10.1016/j.ajo.2011.01.014

13. Chiquet C, Zech J-C, Denis P, Adeleine P, Trepsat C. Intraocular foreign bodies. Factors influencing final visual outcome. Acta Ophthalmol Scand. 1999;77(3):321-325. doi:10.1034/j.1600-0420.1999.770315.x

14. George J, Ali N, Rahman NA, Joshi N. Spectrum of intra-ocular foreign bodies and the outcome of their management in Brunei Darussalam. Int Ophthalmol. 2013;33(3):277-284. doi:10.1007/ s10792-012-9687-1

15. Nicoară SD, Irimescu I, Călinici T, Cristian C. Intraocular foreign bodies extracted by pars plana vitrectomy: clinical characteristics, management, outcomes and prognostic factors. BMC Ophthalmol. 2015;15(1):151-158. doi:10.1186/s12886-015-0128-6

16. Wickham L, Xing W, Bunce C, Sullivan P. Outcomes of surgery for posterior segment intraocular foreign bodies - a retrospective review of 17 years of clinical experience. Graefes Arch Clin Exp Ophthalmol. 2006;244(12):1620-1626. doi:10.1007/s00417-006-0359-6
17. Abu El-Asrar AM, Al-Amro SA, Khan NM, Kangave D. Visual outcome and prognostic factors after vitrectomy for posterior segment foreign bodies. Eur J Ophthalmol. 2000;10(4):304-311. doi:10.1177/112067210001000406

18. Thompson JT, Parver LM, Enger CL, Mieler WF, Liggett PE. Infectious endophthalmitis after penetrating injuries with retained intraocular foreign bodies. National eye trauma system. Ophthalmology. 1993;100 (10):1468-1474. doi:10.1016/S0161-6420(93)31454-5

19. Brinton GS, Topping TM, Hyndiuk RA, Aaberg TM, Reeser FH, Abrams GW. Posttraumatic endophthalmitis. Arch Ophthalmol. 1984;102(4):547-550. doi:10.1001/archopht.1984.01040030425016

20. Yang C-S, Lu C-K, Lee F-L, Hsu W-M, Lee Y-F, Lee S-M. Treatment and outcome of traumatic endophthalmitis in open globe injury with retained intraocular foreign body. Ophthalmologica. 2010;224 (2):79-85. doi:10.1159/000235725

21. Soylu M, Sizmaz S, Cayli S. Eye injury (ocular trauma) in southern Turkey: epidemiology, ocular survival, and visual outcome. Int Ophthalmol. 2010;30(2):143-148. doi:10.1007/s10792-009-9300-4
Clinical Ophthalmology

\section{Publish your work in this journal}

Clinical Ophthalmology is an international, peer-reviewed journal covering all subspecialties within ophthalmology. Key topics include: Optometry; Visual science; Pharmacology and drug therapy in eye diseases; Basic Sciences; Primary and Secondary eye care; Patient Safety and Quality of Care Improvements. This journal is indexed on PubMed

Submit your manuscript here: https://www.dovepress.com/clinical-ophthalmology-journal
Dovepress

Central and CAS, and is the official journal of The Society of Clinical Ophthalmology (SCO). The manuscript management system is completely online and includes a very quick and fair peer-review system, which is all easy to use. Visit http://www.dovepress.com/ testimonials.php to read real quotes from published authors. 